Supporting Information for

\title{
Deriving the Metal and Alloy Networks of Modern Technology
}

Hajime Ohno, ${ }^{* 1,2}$ Philip Nuss, ${ }^{1}$ Wei-Qiang Chen $* * 1,3$ and Thomas E. Graedel ${ }^{1}$

1. Center for Industrial Ecology, Yale School of Forestry \& Environmental Studies, 195 Prospect St, New Haven, CT 06511, USA

2. Graduate School of Engineering, Tohoku University, 6-6-04, Aramaki Aza Aoba Aoba-ku, Sendai, Miyagi 980-8579, Japan

3. Institute of Urban Environment, Chinese Academy of Sciences, 1799 Jimei Road, Fujian 361021, P.R.China

* Corresponding Author: Tel.+81-22-795-5869, Email: ohno@sis.che.tohoku.ac.jp

** Co-Corresponding Author: Tel. +86-592-6190-763, Email: wqchen@iue.ac.cn

Number of pages: 28

Number of figures: 9

Number of tables: 2 


\section{Contents}

1. Methodology

1.1 Conversion of the monetary IO table to a metal IO table

1.2 Disaggregation of sectors for US IO table for 2007

1.2.1 Metal materials (row direction)

1.2.2 Fabricated materials and products (row direction)

2. The definition of the unit in the results

3. Inter-industrial metal networks

3.1 Manganese

3.2 Chromium

3.3 Nickel

3.4 Molybdenum

3.5 Niobium

3.6 Vanadium

3.7 Tungsten

4. Simplified version of simultaneous network of metals

5. Figure for the networks of alloys

6. References 


\section{Methodology}

1.1 Conversion of the monetary IO table to a metal IO table

In the actual mathematical realization of this concept, the basic formula of IO

analysis is defined as follows:

$$
x=(I-A)^{-1} f
$$

where $x, I, A$, and $f$ represent the domestic production vector, a unit matrix, the input coefficient matrix, and the final demand vector. The definition of the input coefficient matrix $A$ is

$$
A=X \operatorname{diag}(x)^{-1}
$$

where $X$ represents the endogenous IO matrix and $\operatorname{diag}(x)$ is the diagonalized matrix of the vector $x$ whose off-diagonal elements are zero. The $(i, j)$-elements of matrix $A$ represent the required input of $i$ for the production of one monetary unit of $j$ (in the US IO table, it is million \$).

Let $X^{*}$ be defined as the base endogenous IO matrix for waste input-output material flow analysis (WIO-MFA) ${ }^{1}$. When $i$ is a material (e.g., aluminum), or a semi-metal product (e.g., a steel mill product), the numbers in the $i$ th row in matrix $X^{*}$ are related to physical units; if not, they are monetary units.

$$
X_{i \cdot}^{*}=\left\{\begin{array}{cc}
\text { physical unit } & \text { when } i \text { represents a material or metal product } \\
\text { monetary unit } & \text { otherwise }
\end{array}\right.
$$


Then, units of the domestic production vector $x^{*}$ and the final demand vector $f^{*}$ are also defined as for $X^{*}$. To calculate the material composition of products $\left(C_{\mathrm{MP}}\right)$, the WIO-MFA is computed by

$$
C_{\mathrm{MP}}=\tilde{A}_{\mathrm{MP}}\left(I-\tilde{A}_{\mathrm{PP}}\right)^{-1}
$$

where $\tilde{A}_{\mathrm{MP}}$ represents the filtered physical input coefficient matrix whose $(i, j)$-element is the physical input coefficient of material $i$ to product $j$. The purported unit of $\tilde{A}_{M P}$ is tonne per monetary unit (but see below for a discussion metal network units).

Let $\tilde{A}_{\mathrm{PP}}$ represent the filtered input coefficient matrix whose $(i, j)$-element is the coefficient of product $i$ to product $j$. Here, "filtered" refers to two different types of filters that are multiplied by input coefficient matrix $A$. The first, the physical flow filter $(\Phi)$, filters non-physical flows such as services, and physical flows that do not incorporate any metal in the final product (such as process catalysts). The second, the yield loss filter $(\Gamma)$, removes the mass of inputs that becomes process waste. So $\tilde{A}$ is calculated as: $\tilde{A}=\Gamma \otimes(\Phi \otimes A)(\otimes$ represents the element-wise product, the so-called Hadamard product).

In our study, we utilize the methodology of the "unit physical input-output by materials (UPIOM ${ }^{2,3}$ " model, which is defined as follows: 


$$
\left.U(m, j)=\left(\begin{array}{c}
\operatorname{diag}\left(C_{\mathrm{MP}}(m, \cdot)\right) A_{\mathrm{pp}} \\
A_{\mathrm{MP}}(m, \cdot)
\end{array}\right) \operatorname{diag}\left(\left(I-A_{\mathrm{PP}}\right)^{-1} f_{j}\right)\right)
$$

Here $U(m, j)$ is an IO table representing a supply chain of a material $m$ to satisfy the final demand of product $j, C_{\mathrm{MP}}(m, \cdot)$ represents the $m$ th row of the matrix $C_{\mathrm{MP}}$, $A_{\mathrm{MP}}\left(m,{ }^{-}\right)$represents the $m$ th row of $A_{\mathrm{MP}}$, and $f_{j}$ represents the vector of final demand for a particular sector's products; its elements are zero except for the $j$ th row. The difference between our study and those of Nakamura et al. ${ }^{2}$ and Nakajima et al. ${ }^{3}$ is the scale of the supply chain. In our calculation, we trace the entire supply chain related to the use of material $m$ by replacing $f_{j}$ in equation (S5) by the full scale final demand vector $f^{*}$. Referring to equation $(\mathrm{S} 1),\left(I-A_{\mathrm{PP}}\right)^{-1} f^{*}$ can be replaced by $x^{*}$, giving

$$
U^{m}=\left(\begin{array}{c}
\operatorname{diag}\left(C_{\mathrm{MP}}(m, \cdot)\right) A_{\mathrm{PP}} \\
A_{\mathrm{MP}}(m, \cdot)
\end{array}\right) \operatorname{diag}\left(x^{*}\right)
$$

Here, $U(m, j)$ in UPIOM model was re-defined as $U^{m}$ because this IO table no longer represents a supply chain for a demand of only single product $j$ but all products in the IO table. According to the definition of the input coefficient matrix $A$ in equation (S2), $A_{P P} \operatorname{diag}\left(x^{*}\right)$ corresponds to the endogenous IO matrix. Then equation (S6) can be transformed to

$$
U^{m}=\left(\begin{array}{c}
\operatorname{diag}\left(C_{\mathrm{MP}}(m, \cdot)\right) X_{\mathrm{PP}}^{*} \\
X_{\mathrm{MP}}^{*}
\end{array}\right)
$$

Consequently, the metal IO table that we developed can be simply formulated as the 
product of the diagonalized $C_{\mathrm{MP}}$ of a material and the IO table, as Nakamura et al. ${ }^{4}$ noted. Finally, let $t$ be the vector of the net trade of products and $w\left(m,{ }^{-}\right)$the mass of waste material $m$ generated in the supply chain. Then the network of metal $m$ in an economic system can be calculated as:

$$
U^{m}=\left(\begin{array}{ccc}
\operatorname{diag}\left(C_{\mathrm{MP}}(m, \cdot)\right) X_{\mathrm{PP}}^{*} & \operatorname{diag}\left(C_{\mathrm{MP}}(m, \cdot)\right) t & w(m, \cdot) \\
X_{\mathrm{MP}}^{*} & t(m, m) & 0
\end{array}\right)
$$

The five steps involved in this process are shown schematically in Figure 1: a disaggregation of sectors relating to metals and alloys, a calculation of the input coefficient matrix, filtrations using the physical flow filter $\Phi$ and the yield loss filter $\Gamma$, a calculation of the material composition of products $C_{\mathrm{MP}}$, and a transformation of the IO table using $C_{\mathrm{MP}}$.

\section{2 Methodology of the disaggregation of sectors for US IO table for 2007}

\subsection{Metal materials (row direction)}

We explain first the disaggregation procedure for rows. The columns are simply disaggregated by allocating values in the original columns based on the production mass of the corresponding disaggregated sectors. The characteristics of the focused metals are given in Table $\mathrm{S} 1$. 
Table S1. Characteristics of metals studied in this research

\begin{tabular}{|c|c|c|c|c|}
\hline Metal & $\begin{array}{l}\text { Principal end-uses and } \\
\text { percentages }\end{array}$ & $\begin{array}{l}\% \text { alloy } \\
\text { uses }\end{array}$ & $\begin{array}{l}\text { \% US import } \\
\text { dependence }^{\#}\end{array}$ & $\begin{array}{l}\% \text { End of life } \\
\text { recycling rate }^{+}\end{array}$ \\
\hline Aluminum & $\begin{array}{l}\text { Transport (28), } \\
\text { construction (24), } \\
\text { packaging (15), electrical } \\
(12), \text { other }(21)\end{array}$ & 73 & 26 & $>50$ \\
\hline Iron & $\begin{array}{l}\text { Construction (48), } \\
\text { machinery (31), transport } \\
(13), \text { other (8) }\end{array}$ & 100 & 12 & $>50$ \\
\hline Copper & $\begin{array}{l}\text { Electrical (26), industrial } \\
(19), \text { transport (13), } \\
\text { plumbing (6), other (36) }\end{array}$ & 8 & 37 & $25-50$ \\
\hline Vanadium & $\begin{array}{l}\text { Alloy steel ( } 75) \text {, carbon } \\
\text { steel (16), other (9) }\end{array}$ & 91 & 100 & $<1$ \\
\hline Chromium & $\begin{array}{l}\text { Infrastructure }(25) \text {, } \\
\text { machinery }(25), \text { transport } \\
(15), \text { other }(35)\end{array}$ & 80 & 62 & $>50$ \\
\hline Manganese & $\begin{array}{l}\text { Carbon steel (90), } \\
\text { aluminum alloys (6), other } \\
(4)\end{array}$ & 96 & 100 & $>50$ \\
\hline Cobalt & $\begin{array}{l}\text { Superalloy (22), batteries } \\
(22) \text {, cutting tools (11), } \\
\text { other ( } 45)\end{array}$ & 22 & 78 & $>50$ \\
\hline Nickel & $\begin{array}{l}\text { Machinery (31), } \\
\text { appliances (28), } \\
\text { construction (17), transport } \\
(15) \text {, superalloy (4), other } \\
(5)\end{array}$ & 95 & 17 & $>50$ \\
\hline Niobium & $\begin{array}{l}\text { Industrial (34), } \\
\text { construction (29), transport } \\
(24), \text { other (13) }\end{array}$ & 98 & 100 & $>50$ \\
\hline Molybdenum & $\begin{array}{l}\text { Industrial (35), stainless } \\
\text { steel (25), alloy steel (11), } \\
\text { superalloy (6), other (23) }\end{array}$ & 81 & 44 & $25-50$ \\
\hline
\end{tabular}




\begin{tabular}{|l|l|l|l|l|}
\hline Tungsten & $\begin{array}{l}\text { Cutting tools (50), } \\
\text { industrial (15), alloy steel } \\
\text { (9), superalloy (9), other } \\
(17)\end{array}$ & 18 & 70 & $11-25$ \\
\hline
\end{tabular}

* Graedel et al., $2015^{5}$

${ }^{\#}$ US Geological Survey, $2008^{6}$

${ }^{+}$UNEP, 2011

As Table 1 in the main paper shows, 24 metal materials for 11 elements are taken into account as sectors in the IO table in this study. Table S2 details the format of the base data for the usage of 24 metal materials based on the U.S. Geological Survey (USGS) ${ }^{6}$, the metal usage data in Graedel, et al. ${ }^{7}$, and the relevance of this information for the IO sectors. For usages of metal materials obtained by the base data that could be assigned to individual IO sectors, the physical quantity values were put in the corresponding columns on the row related to the material. However, usages included in "Nonferrous Alloy" and "Miscellaneous and Unspecified" in the base data needed to be allocated to the IO sectors because there were few data to permit directly connecting these values to specific sectors in the base data. 
Table S2. Format of base data collection for usages of metal materials and relevance with the IO sectors

\begin{tabular}{lll}
\hline Usage of metal material & Relevant sector to input \\
\hline & Carbon steel & Crude steel-Carbon steel \\
\cline { 2 - 3 } & Stainless steel & Crude steel-Stainless steel \\
\cline { 2 - 3 } Endogenous sectors & Alloy steel (including tool steel) & Crude steel-Alloy steel \\
\cline { 2 - 3 } & Cast irons & Ferrous metal foundries \\
\cline { 2 - 3 } & Superalloy & Superalloy \\
\cline { 2 - 3 } & Nonferrous alloy & Allocated \\
\cline { 2 - 3 } & Miscellaneous and unspecified & Allocated \\
\hline & Increasing stock & Change in private inventories \\
\cline { 2 - 3 } Exogenous sectors & Export & Exports of goods and services \\
\cline { 2 - 3 } & Import & Imports of goods and services \\
\cline { 2 - 3 } & Production & Total Commodity output \\
\hline
\end{tabular}

The allocation of the metal material quantities included in nonferrous alloys was based on the input ratio of the sectors before disaggregation into three sectors in the original IO table: "Alumina Refining and Primary Aluminum Production", "Primary Smelting and Refining of Copper" and "Nonferrous Metal (except copper and aluminum) Rolling, Drawing, Extruding, and Alloying". The input ratio $\mathrm{R}_{i j}$ can be calculated by dividing the input value of a sector $i$ to another sector $j$ by the sum of inputs from sector $i$ to all sectors: 


$$
\mathrm{R}_{i j}=X_{i j} / \sum_{j=1}^{n} X_{i j}
$$

Here, $i$ refers to the four sectors before disaggregation, and $j$ is the three alloy sectors in the original $\mathrm{IO}$ table. $\mathrm{R}_{i j}$ for different $i$ are utilized for corresponding metal material sectors to allocate the quantities obtained by base data. However, the input ratio of manganese to alloys was defined separately because the base data stated that $85 \%$ of manganese for nonferrous alloy usage is for iron alloys. Therefore, the remainder of the manganese usage for alloys (15\%) was allocated based on the input ratios of the original nonferrous metal sector for copper and nonferrous alloy sectors.

"Miscellaneous and Unspecified" usage means the direct uses of metal rather than metal used in alloys. The base data for some metals have the quantities of several specific uses in addition to unspecified usage. In those cases, the quantity of use in the corresponding IO sector is specified according to the North American Industry Classification (NAICS) ${ }^{8}$ and its relevant IO sectors ${ }^{9}$. Otherwise, the quantity of "Miscellaneous and unspecified" usage was allocated by input ratio as in the case of the alloy allocation explained above. For that allocation, we referred to the input ratio of the nonferrous metal smelting sector in the original IO to all sectors except the alloying sectors (i.e., $i=$ Primary smelting and refining of nonferrous metal (except copper and 
aluminum); $j=$ all sectors other than alloying sectors). However, because the inputs of the "Primary smelting and refining of nonferrous metal" sector include inputs of all non-ferrous metals except copper and aluminum to other sectors, we cannot use the input ratio of the sector directly to describe the input of an individual metal. Instead, the $(i, j)$-element of filter $\mathrm{B}, \mathrm{b}_{i j}$, was defined as follows:

$$
\mathrm{b}_{i j}=\left\{\begin{array}{lc}
1 & \text { metal material } i \text { appears to be input to product } j \\
0 & \text { otherwise }
\end{array}\right.
$$

For example, when $j$ is the battery manufacturing sector, $\mathrm{b}_{i j}$ is 1 for nickel ( $\left.i=\operatorname{nickel}\right)$ but 0 for niobium ( $i=$ niobium $)$, because nickel is used in batteries but niobium is not. The filter also works to remove the influence of the inputs of precious metals like platinum and gold, which may cause an overly large input ratio when calculated on the basis of monetary inputs from the original non-ferrous metal smelting sector. Accordingly, when $j$ is the Jewelry and Silverware Manufacturing sector, zeros are indicated in $\mathrm{b}_{i j}$ for all $i \mathrm{~s}$. To reflect the filtering, the input ratios for allocating unspecific usages were re-calculated as follows:

$$
\mathrm{R}_{i j}^{\prime}=\mathrm{B} \operatorname{diag}\left(\mathrm{R}_{i j}\right) / \sum_{j=1}^{n} \mathrm{~B} \operatorname{diag}\left(\mathrm{R}_{i j}\right)
$$

This calculation may introduce some uncertainties into the results for metal flows. Because of the lack of available data for the direct use of metals, we cannot simulate the exact uses of individual metals in the model. For most metals, however, over $90 \%$ of the 
uses are well identified (Table S1) and can be unambiguously assigned to IO sectors. In the case of molybdenum and tungsten, relatively large portions (20-30\%) of total flow reflect unspecified uses. Thus, the allocation is likely to distort the results of molybdenum and tungsten flows to some degree. To improve of the accuracy of these results for these metals, more detailed usage data will be needed.

\subsubsection{Fabricated materials and products (row direction)}

As "Fabricated material" sectors, three grades of crude steel (carbon steel, stainless steel, and alloy steel), plus aluminum alloys, copper alloys, and nonferrous alloys including superalloys are introduced into the IO table. The basic information on exogenous sectors in the IO table for fabricated materials is from the USGS Minerals Yearbook, except for nonferrous alloys and superalloys.

Uses of the products of carbon steel and alloy steel were allocated according to the input ratio of the original sector for iron manufacturing. For stainless steel, mill products were disaggregated into seven industrial categories based on Reck, et al. ${ }^{10}$. Uses of $\mathrm{Al}$ alloy and $\mathrm{Cu}$ alloy were allocated based on input ratios of their original sectors $^{11}$. Uses of nonferrous alloys and superalloys could not be allocated in the same way because of the lack of information. Consequently, their inputs were described in 
monetary units. Because the Nonferrous Alloy sector is individually specified in the IO table, flows to subsequent sectors were already in hand.

Superalloys are formally included within the original Nonferrous Alloy sector, but their uses are different from those of other nonferrous alloys. To reflect this difference, input values were specified based on information on superalloy usage ${ }^{12}$, which is mainly for turbine blades $(85 \%)$. In this regard, we note that the original IO table shows no significant direct input of Nonferrous Alloy to either the Aircraft Engine Manufacturing sector or the Turbine and Turbine Generator Manufacturing sector. However, the Forging, Stamping and Sintering sector (hereafter simply the "Forging sector") was the largest input sector for nonferrous metals. To reflect this situation, we created an extra sheet in the IO table to reflect superalloy uses in turbine-related manufacturing. Thus, flows of superalloy-related metals are separately analyzed by the WIO-MFA method. In the extra IO, $85 \%$ of the total input value of the original Nonferrous Alloy sector was allocated to the Forging sector, and the rest to other sectors based on input ratios in the original Nonferrous Alloy sector. In addition, the Forging sector in the extra IO sheet sends $65 \%$ of its total outputs to the Aircraft Engine Manufacturing Sector and $35 \%$ to the Turbine and Turbine Generator Manufacturing sector (as specified by Bedder and Baylis ${ }^{12}$ ). 


\section{The definition of the unit in the results}

What do the numbers in this metal $\mathrm{I} / \mathrm{O}$ table represent? In a traditional $\mathrm{I} / \mathrm{O}$ table the entries in each matrix element are the aggregated transactions between sectors of the economy, and are denominated in monetary units. In a metal I/O table, in contrast, the entries represent amounts of metal that are transferred from one sector of the economy to another. The correspondence between monetary units and metal units is not equivalent across the $\mathrm{I} / \mathrm{O}$ table, however, because monetary transactions in the metal $\mathrm{IO}$ table generally involve other metals and assemblages of the material (that is, the assumption of unique sectoral prices (Weisz and Duchin, 2006) is not satisfied). The flows to initial customers are closely related to the amount of metal exchanging ownership. Subsequent transactions are less and less closely related to the pure metal for which the table was constructed, however, and are more accurately regarded as reflections of the metal-related value of the increasingly complex assemblages that are involved in product manufacturing processes.

In place of the common but (in this case) inaccurate unit of metric tons, we term the aggregated quantities in the elements of a metal IO table as "transformed metal units (TMUs)", and denominate them in hektes. These are terms that parallel the economist's 
monetary units of dollars or yen. (The hekte, pronounced "hecktuh", is thought to have been the first metal coinage, used in Lydia [now Western Turkey] in the $7^{\text {th }}$ century BPE [Paszthory, 1980].

\section{Inter-industrial metal networks}

As the result of sector disaggregation for alloy metals, individual inter-industrial metal networks could be obtained. Looking at overall trend, crude steelmaking has huge connection with metal materials as the first direction of them except tungsten. According to this trend, the final destinations of metals except tungsten are the road transportation sectors and the building and construction sectors. Among 3 different grades of crude steel, manganese, niobium and vanadium are strongly connecting with carbon steel although carbon steel basically contain not so much alloying elements. These elements are mainly used as alloying elements for the high strength low alloyed steel (HSLA steel) ${ }^{13}$. Manganese is widely consumed in steelmaking as a deoxidation agent as well as an alloying element ${ }^{14}$. Chromium and nickel are mainly consumed in crude stainless steelmaking at first, and distributed to various sectors. The difference between chromium and nickel is the use of them for superalloy. Although chromium has the path to superalloy as well as nickel, large share of chromium for the stainless 
steelmaking makes the path relatively small and hard to observe in the figure. Because molybdenum was exported rather than imported like other metals, domestic supply-chain looks relatively weaker. Although the main usages of molybdenum are the steelmaking as well as other metals, molybdenum has some direct paths from the metal material to sectors such as Basic Chemical and Electronic Components. Although it can be clearly obtained that the molybdenum use in the sector categorized in Basic Chemical is catalyst ${ }^{6}$, the uses in Electronics Components sectors is unspecific. As addressed above, because molybdenum has large mass of "Miscellaneous and unspecified" usages in the reference ${ }^{6}$ as well as tungsten, it tend to be strongly affected by the allocation method introducing uncertainties in the results. For tungsten the flow into Metalworking Machinery sector is the largest path. It represents the tungsten usage as a carbide for metal-cutting tools ${ }^{6}$. However as the same as molybdenum, other direct flows are affected by the allocation method. 


\subsection{Manganese}

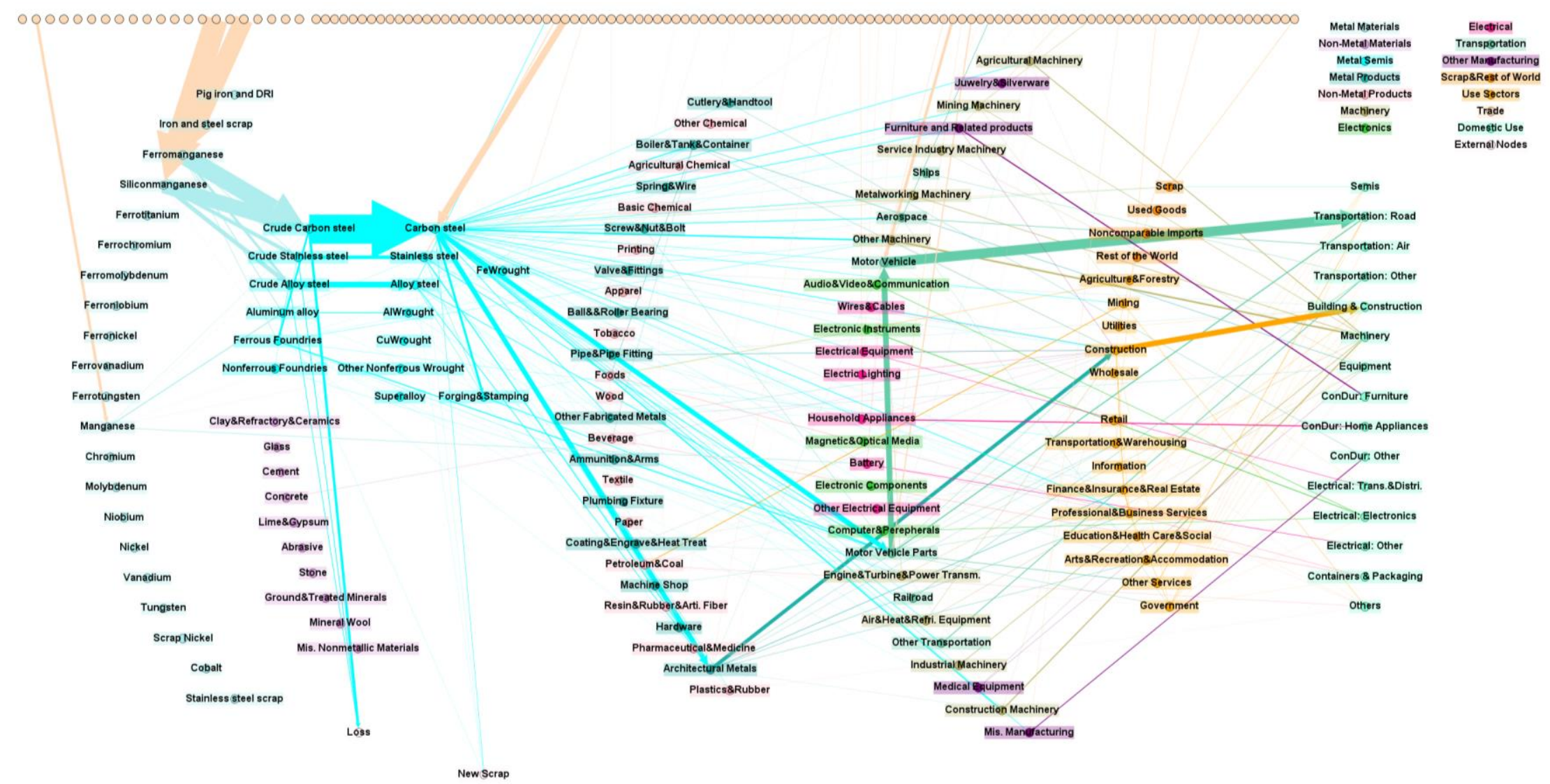

Figure S1 The manganese input-output network for the United States, 2007. The yellow dots at the top of the diagram are origin locations for flows of manganese or manganese-containing products into the U.S. economy. Arrow widths indicate approximate percentages of flows (i.e., edge strengths). The units of flow are hekhtes. Following figures are in the same format. 


\subsection{Chromium}

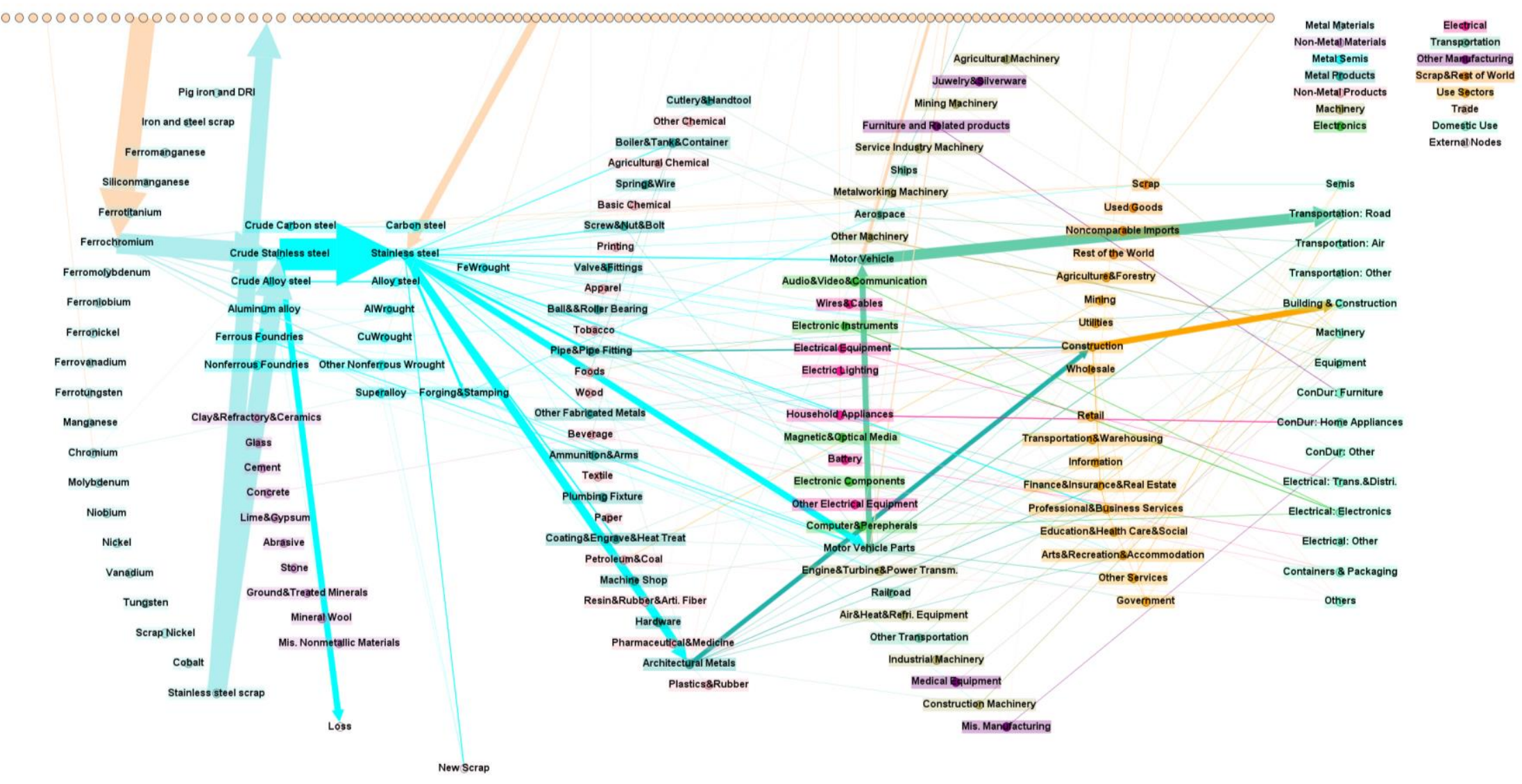

Figure S2 Figure S1 The chromium input-output network for the United States, 2007. 


\subsection{Nickel}

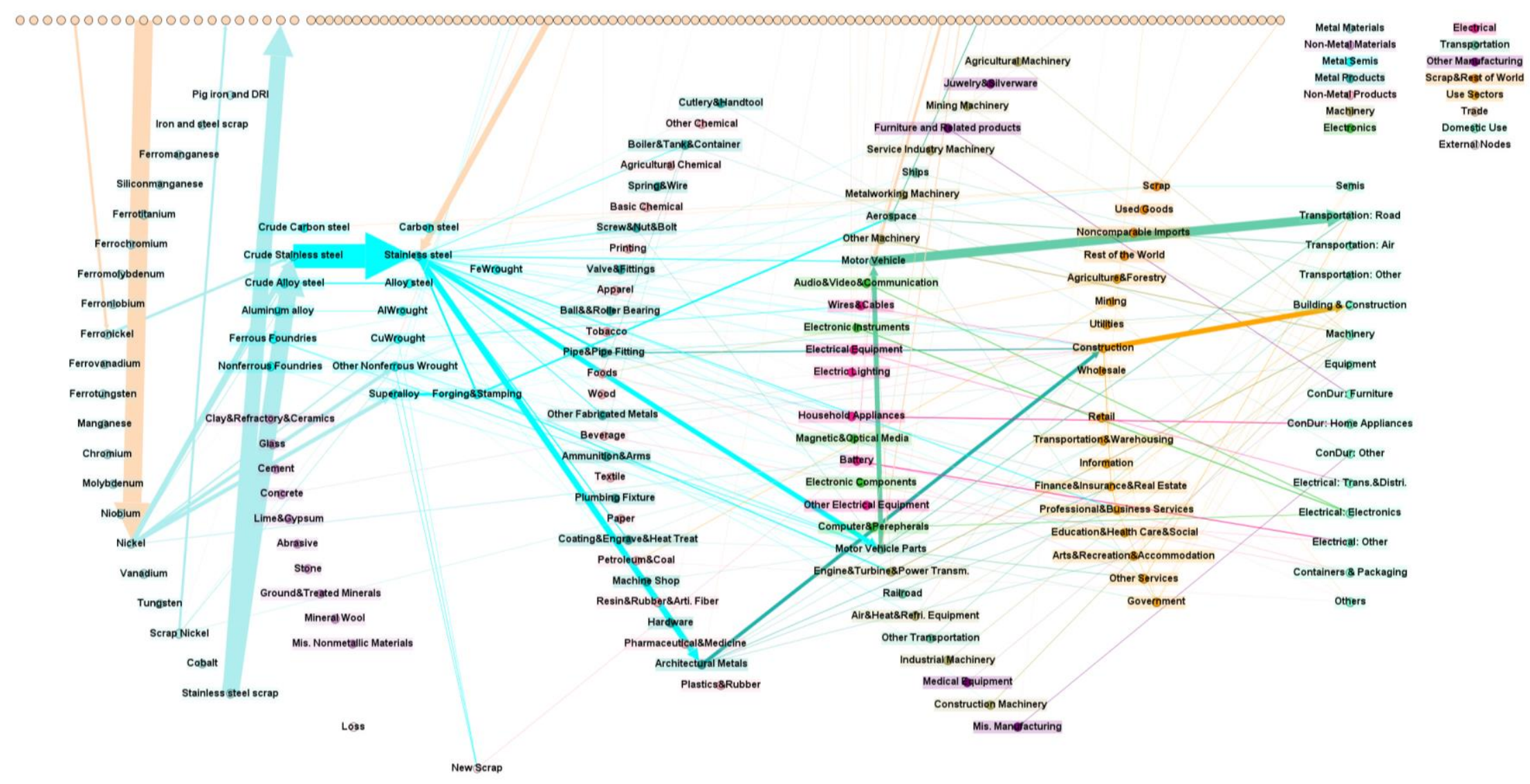

Figure S3 The nickel input-output network for the United States, 2007. 


\subsection{Molybdenum}

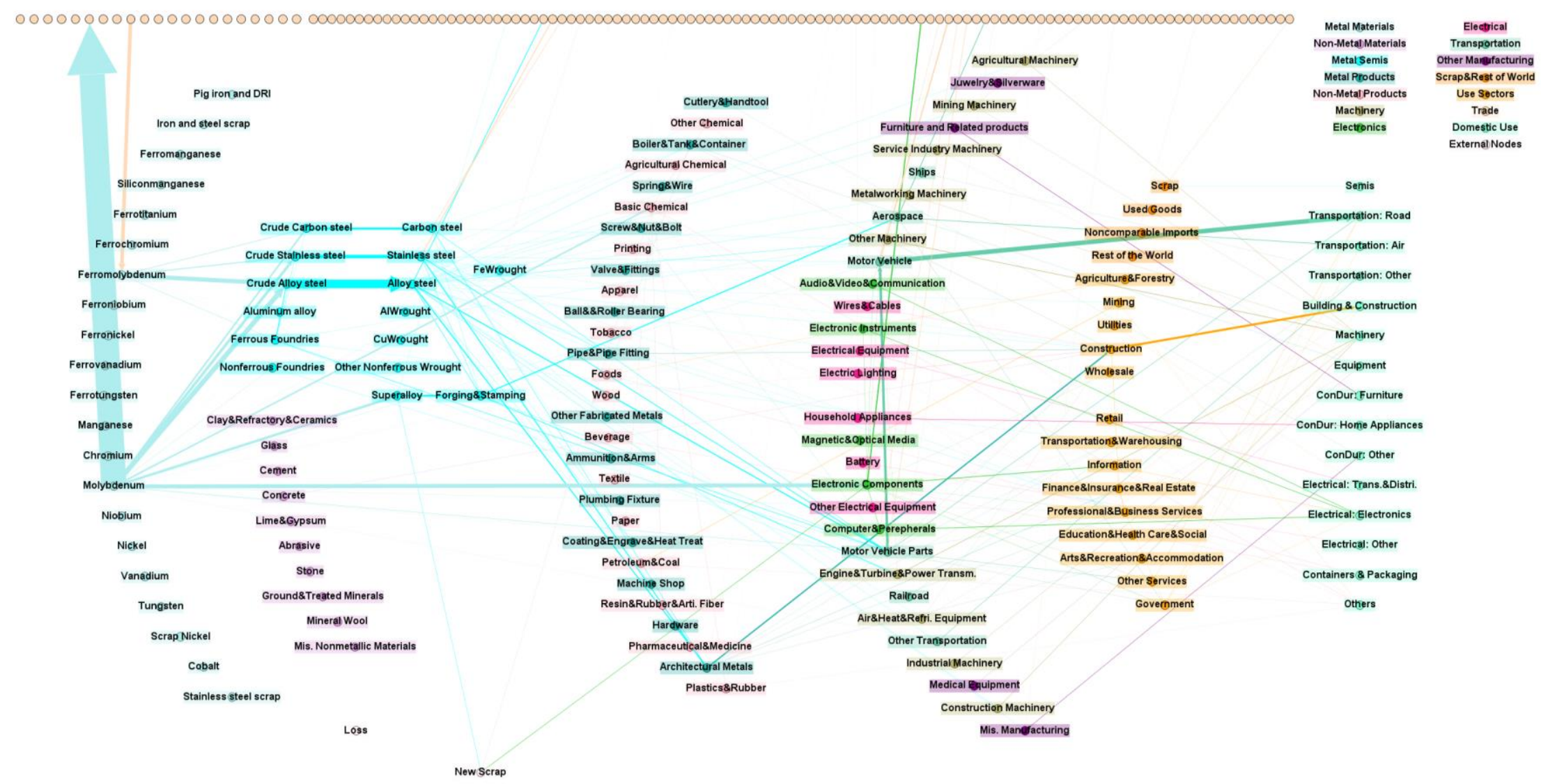

Figure S4 The molybdenum input-output network for the United States, 2007. 


\subsection{Niobium}

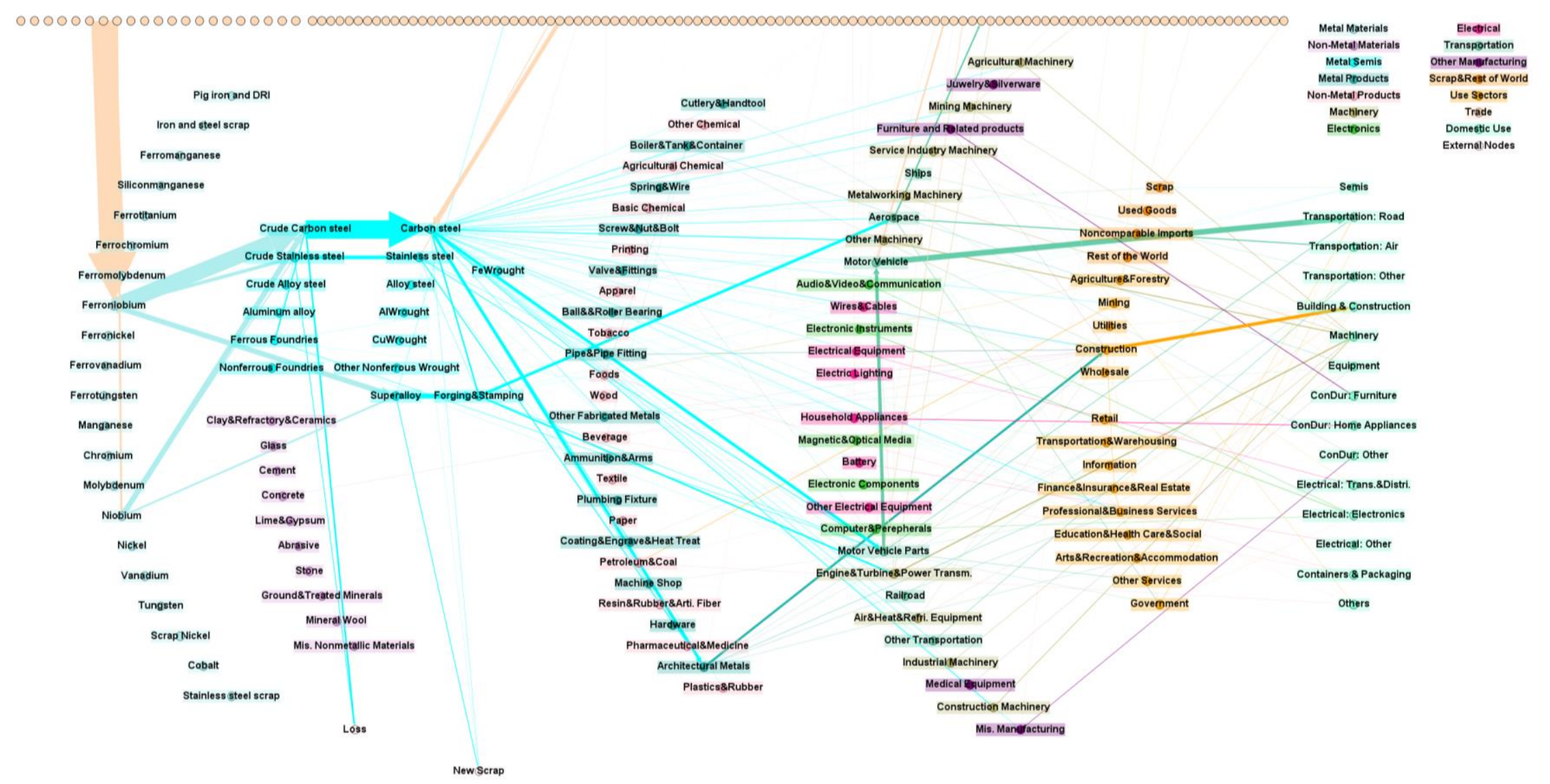

Figure S5 The niobium input-output network for the United States, 2007. 


\subsection{Vanadium}

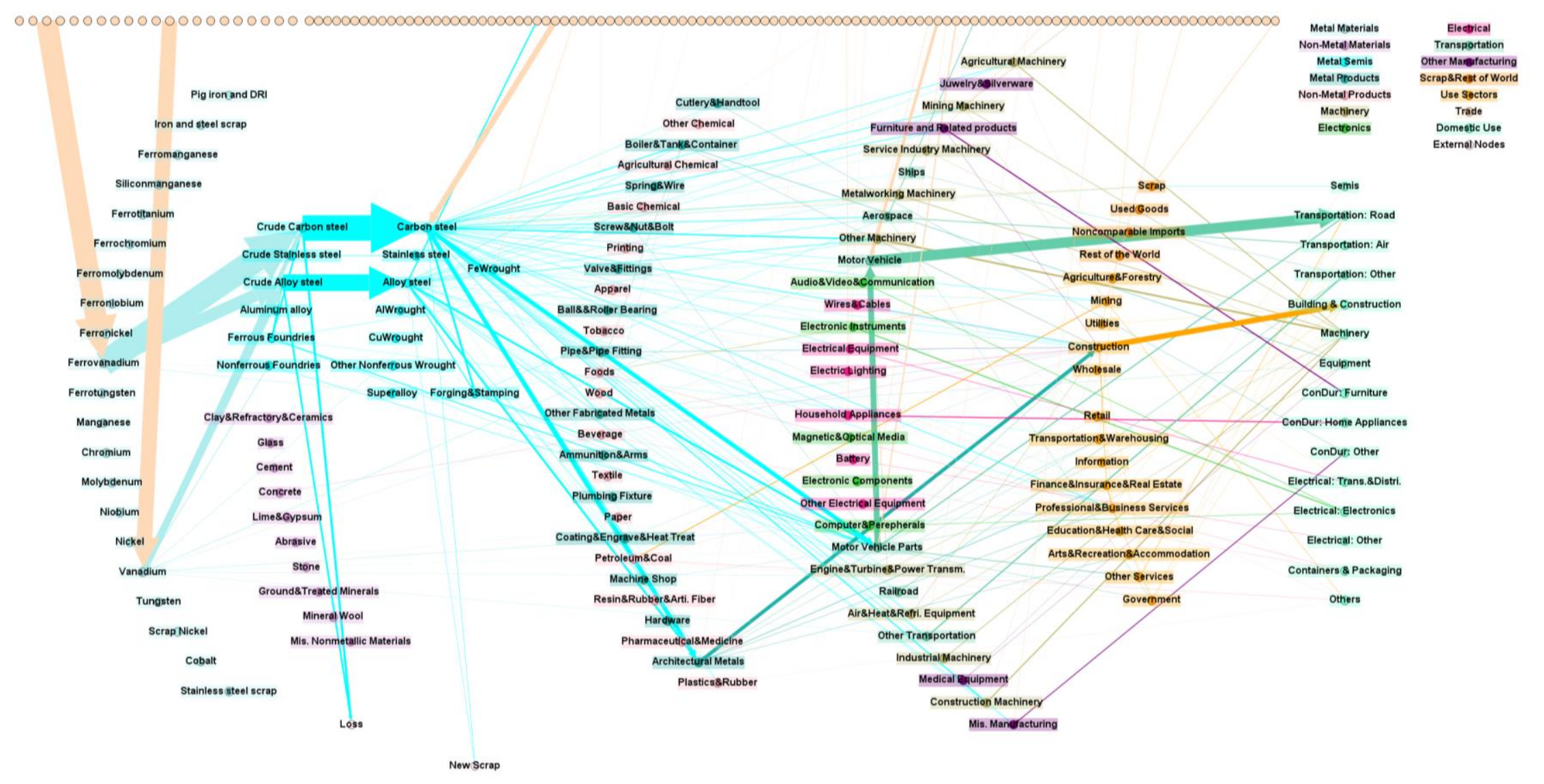

Figure S6 The vanadium input-output network for the United States, 2007. 


\subsection{Tungsten}

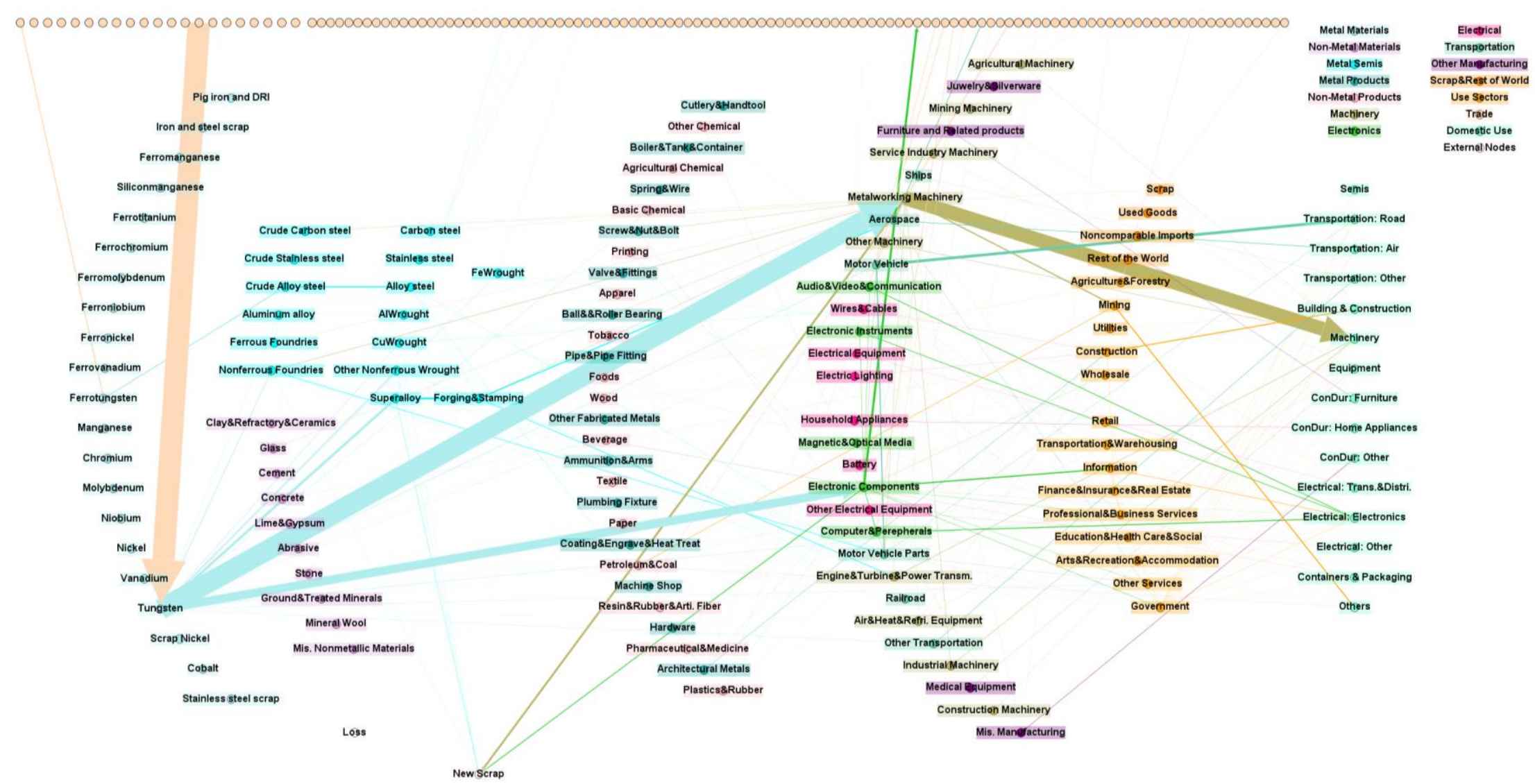

Figure S7 The tungsten input-output network for the United States, 2007. 


\section{Simplified version of simultaneous network of metals}

As an intermediate way to show the complex result simultaneously showing metal flows in 106 sectors, Figure S8 provides much simplified overview.

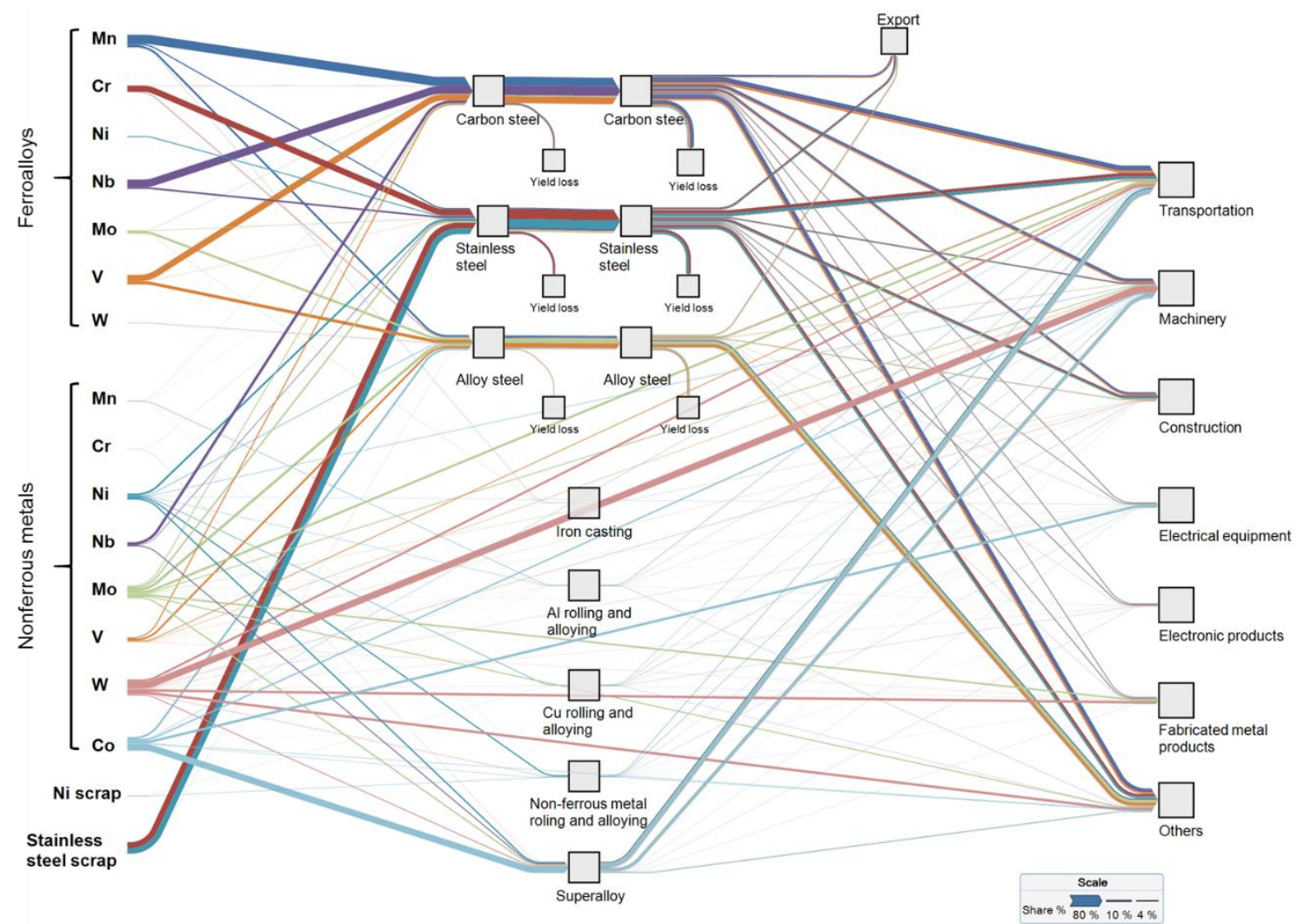

Figure S8 A simplified version of the network of eight metals primarily used in carbon steel, stainless steel, and alloy steel. The sources are the ferroalloy sector and the nonferrous metals sector. The widths of the lines correspond to the fractional uses of each metal (so widths cannot be compared from metal to metal), 


\section{Figure for the networks of alloys}

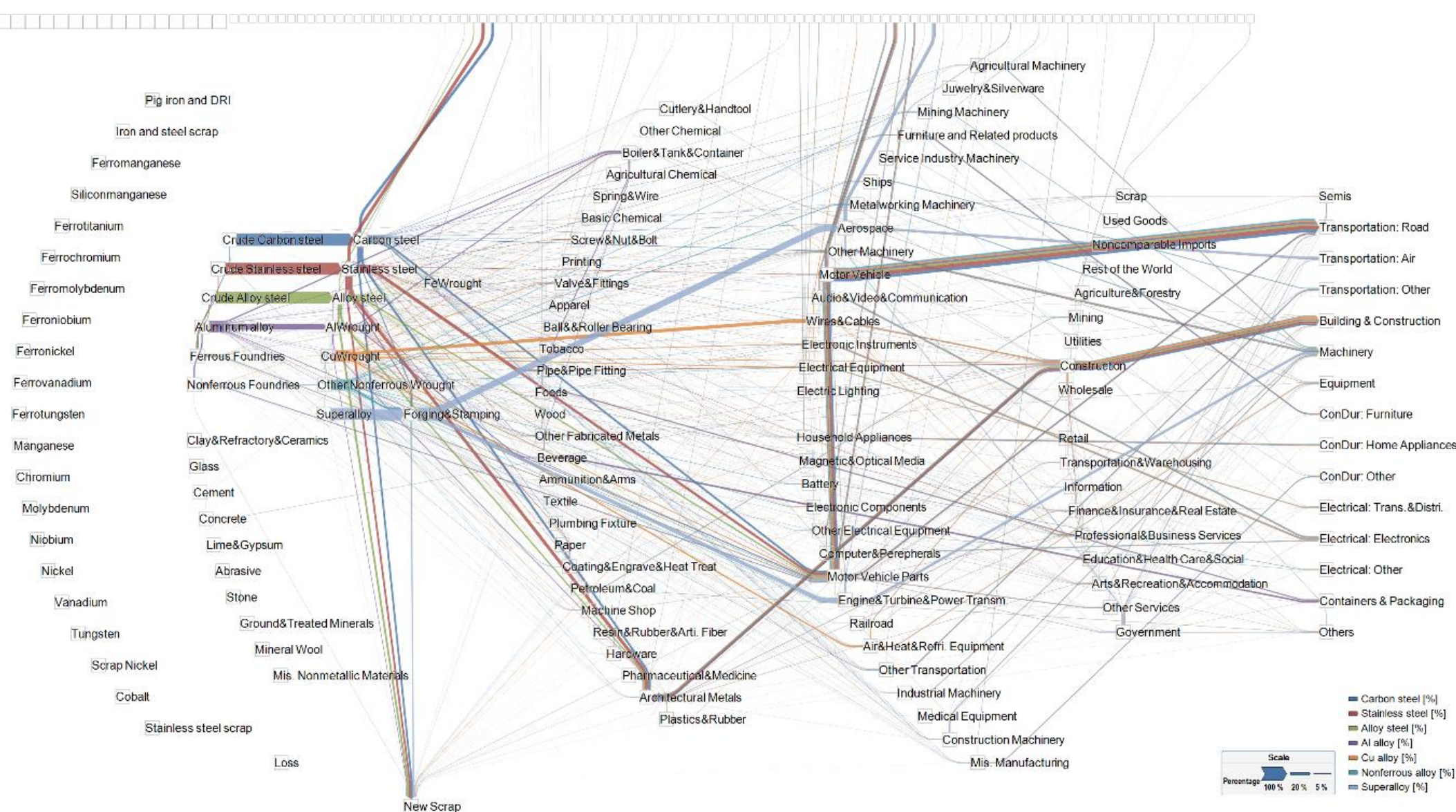

Figure S9 (a) Networks of six alloy groups in the U.S. economy, 2007. Colors represent the individual alloy groups; arrow widths represent edge strengths 


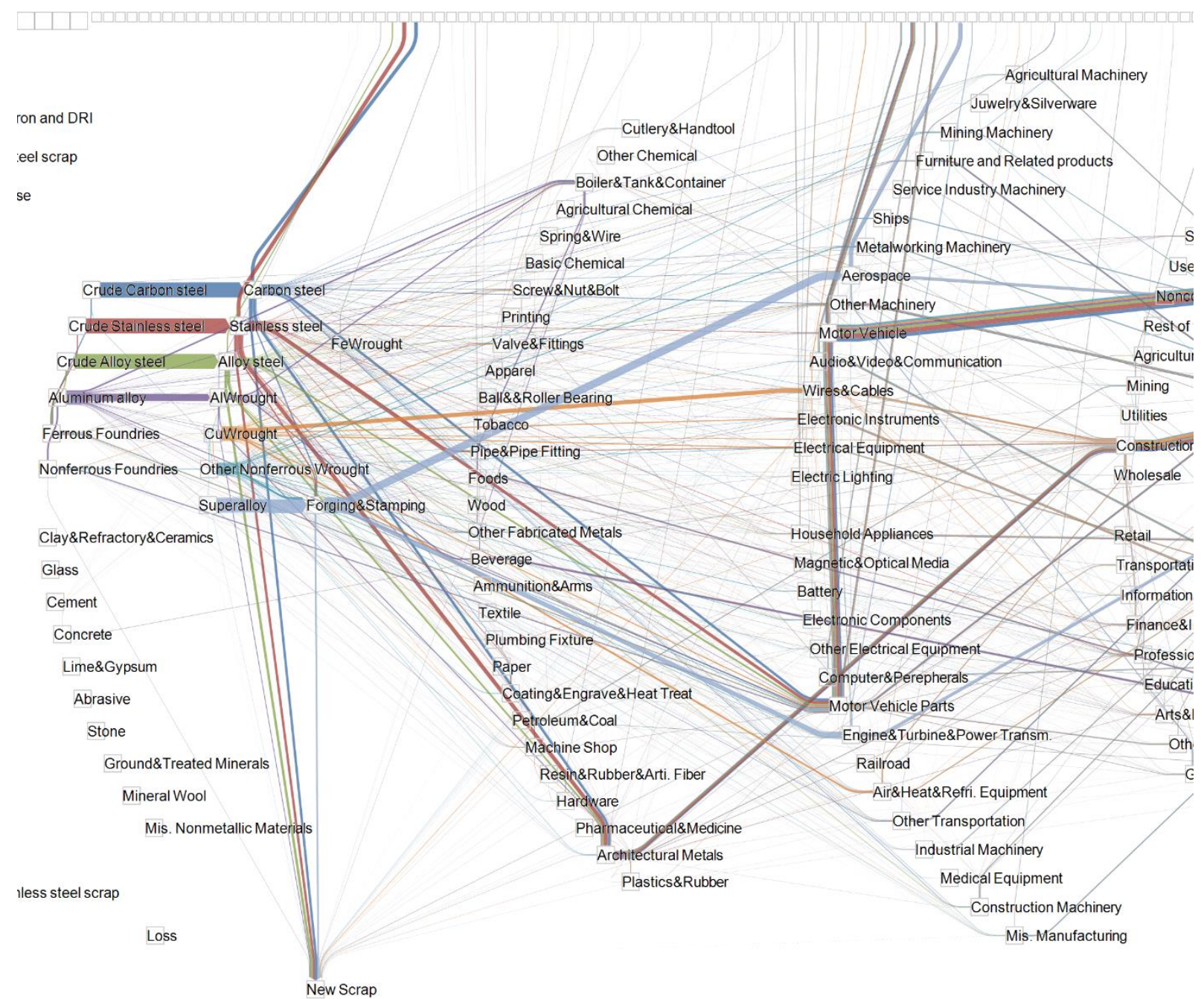

Figure S9 (b) Expanded view of (a) to show detail in the Forging and Stamping sector 


\section{References for SI}

1. Nakamura, S.; Nakajima, K., Waste input-output material flow analysis of metals in the Japanese economy. Mater. Trans. 2005, 46, (12), 2550-2553; DOI 10.2320/matertrans.46.2550.

2. Nakamura, S.; Kondo, Y.; Matsubae, K.; Nakajima, K.; Nagasaka, T., UPIOM: A New Tool of MFA and Its Application to the Flow of Iron and Steel Associated with Car Production. Environ. Sci. Technol. 2011, 45, (3), 1114-1120; DOI 10.1021/Es1024299.

3. Nakajima, K.; Ohno, H.; Kondo, Y.; Matsubae, K.; Takeda, O.; Miki, T.; Nakamura, S.; Nagasaka, T., Simultaneous material flow analysis of nickel, chromium, and molybdenum used in alloy steel by means of input-output analysis. Environ. Sci. Technol. 2013, 47, (9), 4653-60; DOI 10.1021/es3043559.

4. Nakamura, S.; Nakajima, K.; Kondo, Y.; Nagasaka, T., The waste input-output approach to materials flow analysis - Concepts and application to base metals. J. Ind. Ecol. 2007, 11, (4), 50-63; DOI 10.1162/jiec.2007.1290.

5. Graedel, T. E.; Harper, E. M.; Nassar, N. T.; Nuss, P.; Reck, B. K., Criticality of metals and metalloids. PNAS 2015, 112, (14), 4257-62; DOI 10.1073/pnas.1500415112. 6. U.S. Geological Survey (USGS), 2007 Minerals Yearbook. USGS: Virginia, 2008.

7. Graedel, T. E.; Harper, E. M.; Nassar, N. T.; Reck, B. K., On the materials basis of modern society. PNAS 2015, 112, (20), 6295-6300; DOI 10.1073/pnas.1312752110.

8. United States Census Bureau North American Industry Classifiation System. http://www.census.gov/eos/www/naics/ (accessed June 11, 2015),

9. U.S. Bureau of Economic Analysis. Input-Output Accounts Data. http://www.bea.gov/industry/io_annual.htm (accessed June 3, 2014),

10. Reck, B. K.; Chambon, M.; Hashimoto, S.; Graedel, T. E., Global Stainless Steel Cycle Exemplifies China's Rise to Metal Dominance. Environ. Sci. Technol. 2010, 44, (10), 3940-3946; DOI 10.1021/Es903584q.

11. Chen, W. Q.; Graedel, T. E.; Nuss, P.; Ohno, H., Building the Material Flow Network of Aluminum in the 2007 U.S. Economy. Environ. Sci. Technol. 2016, Submitting.

12. Bedder, J.; Baylis, R. Into the melting pot: the superalloy market and its impact on minor metals. http://www.roskill.com/reports/minor-and-light-metals/news/download-roskills-paper-o n-the-superalloy-and-minor-metal-markets/at_download/attachment1 (accessed June 30, 
2015),

13. Nuss, P.; Harper, E. M.; Nassar, N. T.; Reck, B. K.; Graedel, T. E., Criticality of Iron and Its Principal Alloying Elements. Environ. Sci. Technol. 2014, 48, (7), 4171-4177; DOI 10.1021/Es405044w.

14. Nakajima, K.; Yokoyama, K.; Nagasaka, T., Substance flow analysis of manganese associated with iron and steel flow in japan. ISIJ Int. 2008, 48, (4), 549-553; DOI 10.2355/isijinternational.48.549. 